\title{
Hibridismo ou estratégias narrativas? modelos de herói na ficção narrativa de Ngugi wa T'hiongo, Alex La Guma e João Paulo Borges Coelho
}

FÁtima Mendonça Universidade Eduardo Mondlane

RESUMO: COLOCANDO EM QUESTÃO CERTOS USOS DO CONCEITO DE HIBRIDISMOS, O ARTIGO, A PARTIR DE AUTORES COMO O SUL-AFRICANO ALEX LA GUMA, O QUENIANO NGUGI WA T' HIONGO, E O MOÇAMBICANO JOÃO PAULO BORGES COELHO, PROCURA DEMONSTRAR COMO DETERMINADAS ESTRATÉGIAS NARRATIVAS, QUE PODEM CONDUZIR À PERCEPÇÃO DA EXISTÊNCIA DE ELEMENTOS HÍBRIDOS, DERIVAM DE CONSTRANGIMENTOS NARRATIVOS IMPOSTOS TANTO PELOS RESPECTIVOS CONTEXTOS HISTÓRICOS E CULTURAIS COMO POR CARACTERÍSTICAS GENÉRICAS INTRÍNSECAS PARA ALÉM DO PRÓPRIO PROCESSO CRIATIVO, SEMPRE SINGULAR E EVOLUTIVO.

ABSTRACT: QUESTIONING SOME USES OF THE CONCEPT OF HYBRIDISM, THIS ARTICLE FOCUSES AUTHORS LIKE THE SOUTH AFRICAN ALEX LA GUMA, THE KENYAN NGUGI WA T'HIONGO, AND THE MOZAMBICAN JOÃO PAULO BORGES COELHO, IN ORDER TO SHOW HOW CERTAIN NARRATIVE STRATEGIES THAT MAY LEAD TO THE PERCEPTION OF THE EXISTENCE OF HYBRID ELEMENTS DERIVE FROM NARRATIVE CONSTRAINTS, WHICH ARE IMPOSED AT SAME TIME BY THEIR HISTORICAL AND CULTURAL CONTEXTS, AND BY GENERIC INTRINSIC CHARACTERISTICS, BESIDES THE CREATIVE PROCESS ITSELF, ALWAYS UNIQUE AND EVOLUTIVE.

PALAVRAS-CHAVE: NARRATIVA AFRICANA, ALEX LA GUMA, NGUGI WA T' HIONGO, JOÃO PAULO BORGES COELHO, HIBRIDISMO.

KEYWORDS: AFRICAN NARRATIVE, ALEX LA GUMA, NGUGI WA T' HIONGO, JOÃO PAULO BORGES COELHO, HYBRIDISM. 
conceito de hibridismo, tal como outros decorrentes das chamadas teorias póscoloniais, arrasta consigo interpretações e aplicações que por vezes revelam visões do mundo marcadas pela ambiguidade. Estas, por seu turno, integram de forma implícita diversos tipos de memória do passado colonial, o que se repercute em muitos sectores da investigação histórico-literária.

Para alguns, é reconfortante e tentador privilegiar nas actuais literaturas africanas os traços deixados pela convivência com o campo literário produzido o partir da antiga potência colonial. Tal atitude seria teoricamente legítima se se mantivesse no campo das leituras transtextuais. Mas, por vezes, imiscuem-se nelas, mesmo de forma inconsciente, necessidades de branqueamento da história que permeia muita da análise oriunda do antigo centro colonial, legitimada no presente dito pós-colonial por novas relações de poder. ${ }^{1}$ Estas novas relações, predominantemente económicas, acabam por reintroduzir pela sua acção (editoras, cooperação institucional etc.), muitos dos tópicos caros à justificação da empresa colonial, nomeadamente o dos traços deixados pela sua acção e que se integrariam sem sobressalto nas culturas dai resultantes, o que me parece estar a dois passos do actual conceito de hibridismo. As ambiguidades resultantes da acção de instituições transnacionais, marcadas pelo uso da mesma língua (lusofonia, francofonia ou a sua variante Commonwealth), mostram as armadilhas ideológicas a que este conceito está sujeito.

Num outro extremo houve - e há - aqueles para quem é simbolicamente importante rasurar essa relação e substituí-la pelo regresso a um passado de oralidade primária a-histórico ou, numa outra variante, diabolizar a memória colonial. Transformado numa espécie de essência africana, esse passado a-histórico, mítico e idílico do universo de oralidade passaria a impregnar o corpus literário escrito e a partir dele constituir o único e "autêntico" cânone.

Nos finais dos anos 60 após as independências do Uganda e do Quénia assistiu-se na área geográfica da costa africana do Índico a um protagonismo literário com essa componente, a partir das universidades de Makerere e do Quénia , de que algumas obras dos escritores Okot P’Bitek (Song of Lawino) e

\footnotetext{
1 Ver o texto de António Vitorino, proeminente personalidade ligada ao Partido Socialista Português, que, na qualidade de Comissário do Concurso 7 maravilhas de origem portuguesa no Mundo, onde estão incluídos monumentos e locais ligados à história do tráfico de escravos: “(...) constituem expressão da forma ímpar como os portugueses se inseriram em terras e comunidades do ponto de vista étnico, cultural, linguístico e religioso".Cf. www.7maravilhas.sapo.pt
} 
Ngugi wa T'hiongo, para além dos seus próprios posicionamentos como universitários foram paradigma, embora em graus diferentes e por vezes opostos.

Mais a sul, foi Ezekiel Mphalele quem, no contexto político criado pelo sistema do apartheid, se bateu pela valorização dos códigos temáticos e ideológicos na escrita literária de forma a integrar nela tradições e valores étnicos sustentados por uma forte e dinâmica arte verbal oral em línguas zulu, khosa ou sutho.

Havia antecedentes africanos para estes posicionamentos, marcados, é certo, por alguma heterogeneidade, mas que partilhavam o desejo de revitalizar a literatura escrita num novo contexto político, com códigos temáticos ou estilísticos provenientes de tradições orais africanas, em oposição à escrita subsidiária da estética ocidental, estimulada pelas instituições coloniais.

$\mathrm{Na}$ verdade, os primeiros romances do escritor nigeriano Chinua Achebe Things fall apart (1958) e The arrow of God (1964)), podem ser vistos como uma espécie de marco fundador de uma nova atitude que se prolonga até hoje em países de independência mais tardia, como Angola e Moçambique, e que o próprio Chinua Achebe sintetizou em anos recentes ao considerar ser um dos desígnios do romance africano o tornar-se instrumento formal da reinvenção de uma cultura africana, de uma nova comunidade nacional, face à perda que a colonização representou.

Colonisation was the most important event in our history for all kinds of angles (...) most of the problems we see in our politics derives from the moment when we lost our initiative to other people, to colonisers. [...] (Gikandi, 1991: 4)

Podemos, portanto, perceber a lógica que levou a que a memória do colonialismo se cruzasse com necessidades e opções estéticas e que, nesse cruzamento, emergissem diversas atitudes no campo literário, que tanto podem passar por variadas formas de recepção e apropriação do "outro-estrangeiro “, como pela sua parcial ou total substituição pelo “ ”primordial-próprio ”.

Esta forma de diálogo da literatura com o passado colonial em toda a sua extensão tem produzido inúmeras situações discursivas hoje identificadas de forma generalizada como bibridas, sob influência do posicionamento teórico de Homi Bhabha, (Bhabha,1990: 292) que as caracteriza como “(...) complex strategies of cultural identification and discursive adress that function in the name of the "people' or the 'nation'(...)" 
Convém, no entanto, recordar que Bhabha introduziu o conceito a partir de uma perspectiva sociológica e que a sua transposição para o campo literário pode conduzir às armadilhas que referi. De qualquer modo e para clarificar a minha posição retomo aqui as palavras de Arjun Appadurai (Appadurai, 1996 : 139), a propósito da forma como o cricket se 'indianizou': 'la décolonisation, pour une ancienne colonie, ne consiste pas simplement à démanteler les habitudes et les modes de vie coloniaux, mais aussi a dialoguer avec le passé colonial." Prefiro então ampliar o significado do conceito integrando nele os conceitos de transculturação e de transtextualidade, porque possibilita a leitura do corpus literário produzido por e contra os sistemas literários trazidos pela colonização, como transformações e apropriações das suas formas, com utilização de estratégias específicas que assim respondem à necessidade de forjar novos sistemas, isto é, a literatura nacional. São essas estratégias que, deixando entrever culturas diversas (orais e escritas), textualizam a nação, na perspectiva em que Benedict Anderson (Anderson, 1983) encara a construção dos elementos de pertença a um espaço nacional e que, do ponto de vista da história literária, legitimam o aparecimento de um novo cânone.

Estes são os pressupostos que orientam a minha tentativa de mostrar, com três textos de ficção $A$ Walk in the night (1962) de Alex La Guma $A$ grain of wheat (1967) de Ngugi wa 'T' hiongo, e Setentrião (2005) de João Paulo Borges Coelho), como em alguns escritores africanos se evidenciam determinadas estratégias narrativas que podem conduzir à percepção da existência de elementos híbridos.

De facto, como tentarei demonstrar, essas estratégias decorrem predominantemente de constrangimentos narrativos impostos tanto pelos respectivos contextos históricos e culturais como por características genéricas intrínsecas para além do próprio processo criativo, sempre singular e evolutivo.

Mostrar-se-á com estas três narrativas como se produzem diversas apropriações no nível da construção das personagens, tendo como efeito, do ponto de vista da recepção, uma eficácia que legitima o seu reconhecimento como elementos integrantes dos sistemas literários nacionais, passíveis por isso de reiteração, o que nos pode levar a colocar a pergunta inicial: Hibridismo ou necessidades narrativas?

Nos casos em análise há uma proximidade temporal na produção dos textos de La Guma e Ngugi (década de 60) enquanto os de Borges Coelho surgem quatro décadas depois. No entanto existe neles aquilo que me parece ser um ele- 
mento pertinente e que, de alguma forma, se vem reiterando na ficção africana: a configuração do(s) protagonista(s) modelado pelo paradigma do anti-herói.

Relativamente a $A$ walk in the night e $A$ grain of $W$ heat é possivel estabelecer de imediato analogias entre a personagens de Willy Boy, o jovem marginal de um subúrbio de Cape Town que assassina sem motivação racional um velho branco e que, na fuga, a polícia tem o mesmo destino da sua vítima. Mugo, que é tido pela sua aldeia como um dos heróis da independência do Quénia, nas vésperas das celebrações se declara como o traidor que conduziu pela denúncia o combatente dos Mau Mau, Kihika, à morte, pelos britânicos, acabando ele próprio por ser executado pelo novo poder que começa a instituir-se.

É fácil associar o comportamento destes personagens e as suas motivações psicológicas às personagens do universo dostoiyevskiano, movidas por conflitos interiores. Contudo, diferentemente delas, estas movem-se num cenário social que quase justifica as acções cometidas. Esse cenário é construído de forma realista pelas sucessivas analepses que enquadram o historial de Mugo no colonialismo britânico (no caso de Ngugi), ou pelas descrições do quotidiano degradado do bairro mítico de Cape Town district six, dominado pela omnipresença do poder repressivo do apartheid sob a forma da polícia, no caso de La Guma. Em ambas as situações a tendência para a exterioridade do ponto de vista do narrador institui a ambiguidade ao longo das duas narrativas, cujos desfechos são deixados sem julgamento. Se associarmos estas duas componentes perceberemos que é da sua combinação que resulta a disforia de ambas as personagens e que as faz escapar ao modelo literário que poderíamos ligar a cada uma dessas mesmas componentes: por um lado uma tendência psicologizante, valorizadora do drama existencial vivido pelas personagens (carência afectiva no caso de Mugo, falta de objectivos no caso de Willy Boy) e que as conduz ao crime; por outro uma tendência próxima do realismo-socialista, com a criação de um cenário marcado pelo conflito social e político (colonização britânica num caso apartheid no outro) a determinar pares marcados de protagonistas; positivo vs negativo.

Falaríamos então aqui de hibridismo, no sentido de que nenhuma destas narrativas se filia de forma absoluta ou precisa numa destas duas tendências, mas se movem, outrossim, numa espécie de entre-lugar, do qual emerge o anti-herói. Mas o que me parece de realçar é que, pelo distanciamento que cria relativamente a esses outros gestos literários, estas obras se apresentam 
com um efeito de diferença que a recepção acabou por legitimar como identificadora de um espaço literário próprio (literatura queniana e literatura sulafricana), dando origem à cristalização de um modelo que, percebido inicialmente como bíbrido, se tem multiplicado como tendência noutros escritores africanos, contribuindo assim para uma identificação genérica .

Como consequência, cada vez mais nos deparamos, nestas literaturas, com modelos de heróis problemáticos que se inscrevem numa visão do mundo perpassada por elementos de ordem filosófica e ou ideológica que sustentam as chamadas teorias pós-modernas.

A já relativamente extensa obra de João Paulo Borges Coelho é paradigmática desta postura. Se considerarmos alguns dos elementos estruturantes das cinco narrativas que integram Setentrião, em função deste aspecto, reconheceremos uma visão do mundo onde estão subjacentes princípios filosóficos que, embora oriundos de um passado distante (o das grandes heresias cristãs do Século XII), se recompuseram em formas de pensamento heterodoxo contrário às dicotomias produzidas pelo Iluminismo, imiscuídas nas chamadas grandes narrativas (sejam elas do judaísmo-cristianismo ou do marxismo).

O que nos atinge ao ler estes textos é a evidência de ausência de fronteiras entre Uns e Outros, a indeterminação das respectivas qualidades e defeitos, a permuta constante entre os conceitos de Bem e de Mal, de onde resulta um efeito de perplexidade perante a realidade descrita/narrada, a qual se recusa permanentemente a ser captada de forma imediata, instituindo-se preferencialmente como espaço de questionamento e de incerteza. Os finais em aberto, o clima enigmático criado pelos narradores, a fluidez das suas intromissões, ora afirmando, ora negando, ora instalando dúvidas, reenviam esta escrita para o espaço da incerteza e da indeterminação, da dúvida e da interrogação, logo, da heterodoxia.

Embora cada uma das narrativas se desenrole em espaços diferentes e referenciáveis de Moçambique (Ilha de Moçambique, Beira, Santa Carolina, Quelimane e Ibo) é possível perceber que as personagens mantêm uma invariância: a de se constituírem como pares constitutivos de identidades bifrontes, intercambiando entre si regras e valores, sem que aos leitores seja fornecida a comodidade de um reconhecimento seguro, que as aparente com o já conhecido e consagrado. Quem estará do lado certo? O cliente/estranho que profana pelo acto da compra o pano bordado de Jamal/alfaiate? Ou o alfaiate/ patrão Sr.Rachid, cuja fé islâmica se adequa pragmaticamente ao meio social? 
Ou antes, o alfaiate/empregado Jamal que na sua viagem interior, corporizada no bordado dos caminhos que levam a Meca, ambiciona recuperar a pureza da mesma fé pela anulação da distâncias entre a Ilha e o espaço sagrado de Meca, alienado da(s) realidade(s) que a sua condição lhe impõe?

E para onde se inclina a nossa afeição? Para o Povo aglomerado no Grande Hotel da Beira, pássaros aprisionados naquela imensa gaiola, e ameaçado de expulsão pelas autoridades, para depois, liderado pelo rapazito a quem chamavam 302, caminhar em direcção à praia para lá ocupar os velhos barcos encalhados e produzir nova onda de perturbação e de tragédia? Ou para o desesperado Comandante que, impotente, decide fazer regressar a Força à terra firme em passo dobrado e já molhando as botas novas porque lhe escapava a sageza do miúdo, porta-voz de uma multidão semináufraga de novo ameaçada pelas águas da tempestade?

Que julgamento faremos do Passado? Do Pide Teodoro capaz de se apaixonar? De uma Marta/viva, futura Marta/morta, presa ao sortilégio do corpo, vítima e algoz ao mesmo tempo? De quem nos afastamos mais rapidamente, quem repudiamos com maior veemência, se essa definitiva transição (a morte ou o esquecimento?) nos faz ressoar da voz de Marta/morta (...) estar lutando no lodaçal das coisas para não nos afundarmos, para logo depois pairando por cima delas como se voássemos?

$\mathrm{E}$ com quem concordamos se nem sabemos com que concordar? Com o chefe da equipa, cuja conclusão ficamos a desconhecer ou com os outros, que concluem diferentemente, todos investigando o caso de Hermes? Conclusões oscilantes, como oscilante (para além de caótico) é o próprio discurso da personagem (vítima de crime ou criminosa?), de configuração multiforme respondendo à simbologia do próprio nome (Hermes, deus grego da Eloquência, dos comerciantes e dos ladrões e também mensageiro dos Deuses ).

Poderia a última narrativa Ibo Azul escapar a este trânsito da fluidez de acções contrárias, de comportamentos que escapam ao juízo ético? Aparentemente sim, porque personagens abstractas, o homem que chega, - o estrangeiro - e a mulher solitária, esgravatando a areia da praia no seu trabalho diário parecem destinadas a um encontro solar, orientadas pelo ritmo poético da descrição:

Repara na pele dela, nas cicatrizes pequenas que o acaso ali foi riscando. Uma rocha aguçada, uma concha fina como lâmina, avisando-a de maior prudência 
(...) E o que o homem via alimentava aquilo que a sua febre imaginava (...) Vai subindo até se deter na gelada máscara de m’siro e se sentir invadido pela ambiguidade desse frio. Uma máscara que, apesar de ajudar a explosão do olhar que dela emana, lhe esconde todavia o sentido (p.206-207).

No entanto o clímax do encontro é invertido pelo domínio de leis da física e do mundo, as que regulam o Tempo e o Espaço. O encontro fugaz medido pelo Tempo que dura o Boa tarde/Boa tarde... e pelo Espaço concentrado do cruzamento, reduz-se a esse momento mágico, o único que escapou às regras, contra as quais o narrador/personagem se revolta, as regras que impõem bierarquias rígidas nas formas como os acontecimentos se sucedem, sempre os dóceis efeitos colando-se às usas, quase nunca o contrário, mesmo se por vezes se interpõe o ilusório espanto do acaso. Entramos de novo no campo preferido dos narradores destas histórias, o da indeterminação e da fuga à lógica das evidências impostas pelo racionalismo.

Resumindo e como conclusão: são várias as estratégias de distanciamento cujos efeitos de leitura fazem os textos de que me ocupo escapar quer ao fascínio antropológico e histórico, que tanto parece ainda seduzir alguns estudiosos das literaturas africanas, quer à integração mecânica nesta igualmente sedutora categoria de hibridismo.

Obrigamo-nos assim a ler estas narrativas por aquilo que são i.e. ficção literária, orientadas pela complexidade das relações que entretecem com os vários níveis da actividade humana.

\section{Referência Bibliográfica}

ANDERSON, Benedict (1983) - Imagined Communities: Reflections on Origin and Spread of Nationalism. London: Verso.

APPADURAI, Arjun (1996) - Après le colonialisme. Les conséquences culturelles de la globalisation. Paris:Payot. [tit.original Modernity at Large. Cultural Dimensions of Globalization, University of Minnesota Press].

BHABHA,Homi (Ed.) (1990) - Nation and Narration. New York: Routledge.

COELHO, João Paulo Borges (2005) - Índicos indícios I-Setentrião . Lisboa: Caminho.

GIKANDI, Simon (1991) - Reading Chinua Achebe. London: James Currey.

LA GUMA, Alex (1962) - A walk in the night. Ibadan:Mbari.

T’HIONGO, Ngugi wa (1967) - A grain of wheat. Nairobi: Heinemann. 